EUROPEAN JOURNAL OF ENVIRONMENT

AND

PUBLIC HEALTH
European Journal of Environment and Public Health,

2017, 1(1), 01

ISSN: 2468-1997

\title{
A Snapshot of Racial and Geographic Distribution of Lung and Bronchus Cancer Incidence and Mortality in Mississippi, 2008-2012
}

\author{
Danielle R. Bogan ${ }^{1 *}$
}

\section{${ }^{1}$ Jackson State University, MS, USA}

*Corresponding Author: dbogan05@yahoo.com

Citation: Bogan, D.R. (2017). A Snapshot of Racial and Geographic Distribution of Lung and Bronchus Cancer Incidence and Mortality in Mississippi, 2008-2012. European Journal of Environment and Public Health, 1(1), 01. https://doi.org/10.20897/ ejeph.201701

Published: June 30, 2017

\begin{abstract}
To identify disproportionate burden for lung and bronchus cancer incidence and mortality rates in Mississippi from 2008-2012. Lung and bronchus cancer remains a major public health burden in the United States and Mississippi. We examined data from 2008 to 2012 for lung cancer incidence and mortality rates by demographics (age, sex, race) and geographic (Public Health Districts, and urban/rural) characteristics to identify potential health disparities. Data were extracted from the Mississippi Cancer Registry (MCR). It represents age-adjusted incidence and mortality rates per 100,000 population to the 2000 U.S. standard population and 95\% confidence intervals. During 2008-2012, 12,579 people (overall rate of 78.63 per $100,000)$ were diagnosed with lung cancer in Mississippi. Overall, Whites in urban areas had a higher incidence (80.9) rate and Blacks had a higher mortality (62.94) rate. Based on the findings of age, sex, race, and geographic disparities, it is suggested that there is a need for more effective community-based interventions and preventative measures for cultural sensitive groups to reduce the burden of lung cancer in Mississippi. It also helps to coordinate a more comprehensive approach for the control of cancer planning efforts.
\end{abstract}

Keywords: lung cancer, Mississippi, racial distribution, geographic distribution, health care policy

\section{INTRODUCTION}

Mississippians of various backgrounds have encountered an enormous impact of cancer. Although the burden of cancer affects all who reside in 82 counties and 9 Public Health Districts, the distribution of its impact is not equally dispersed across the entire state. Throughout Mississippi, cancer incidence and mortality continue to despite the advancement of science and technology in cancer prevention, early screening detection, and treatment. Consequently, lung and bronchus cancer remains a major health burden as the leading cause of death and the $2^{\text {nd }}$ most frequently diagnosed in the United States and Mississippi (MCR, 2017). Epidemiological studies have reported racial, ethnic, and geographic disparities in lung cancer incidence and mortality rates in the South (Mitchell, et al. 2009; Underwood, 2012; Xiaoling, 2010). Thus, National Program of Cancer Registries (NPCR) has consistently reported low lung cancer incidence and mortality rates among the White population with the rates disproportionately high for the Black population for U.S. and various states. But, when considering all cancer sites, Blacks, particularly Black males have the highest occurrence and death rates per year per 100,000 compared to their counterparts (National Cancer Institute [NCI], 2007). Racial differences in lung cancer incidence patterns reflect secular trends between men and women due to the prevalence of cigarette smoking over the past 50 years. Mississippi is ranked as the $3^{\text {td }}$ highest state in the U.S accounting for $24.8 \%$ adults who currently smoke. (Nguyen, Marshall, Hu, \& Neff, 2015). Cigarette smoking is the most modifiable risk factor and accounts for $87 \%$ lung 
cancer deaths and 30\% of all cancer-related deaths (Giddens, 2013), but the risk increases with the amount and duration of tobacco use. Consequently, 20-30\% of nonsmokers exposed to secondhand environmental tobacco smoke in the environment develop lung cancer (US Department of Health and Human Services [HHS], 2014). While, smoking may primarily be the cause of high rates of lung and bronchus cancer in the U.S. and Mississippi, residing in rural and Appalachian regions have a higher smoking prevalence nationwide (American Lung Association, 2016). In addition to tobacco use, exposures to occupational and environmental toxins, lack of access to healthcare, and socioeconomic status (SES) may influence the lung and bronchus cancer in rural compared to urban areas (Singh, Williams, Siahpush, \& Mulhollen, (2011).

However, many local, state, and nationwide initiatives have been implemented to promote awareness in the communities that are affected. Mississippi State Department of Health (MSDH) has worked in collaboration with the Center for Disease Control and Prevention (CDC) to establish a comprehensive cancer control program by conducting several activities to reduce, control, and prevent occurrence and deaths associated with cancer and to improve a substantial quality of life for all Mississippians (MSDH, 2006). Furthermore, public health districts, cancer coalitions, key stakeholders, and various organizations continue to work together to address the gaps and barriers in the entire state. Nevertheless, health care factors affecting these areas may play a pivotal role in cancer prognosis, stage, survival, mortality, and recurrence for minorities and the poor who reside in underserved areas.

Although, the overall cancer incidence and mortality are declining in other states, trends in lung and bronchus cancer are varied throughout 9 Public Health Districts in Mississippi. The purpose of this review will delineate data to address the status of lung and bronchus cancer by describing the incidence and mortality rates among race, age, gender, and Public Health Districts (I-IX) in the state of Mississippi from 2008-2012.

\section{METHODS}

The Mississippi Cancer Registry (MCR) is a gold-certified statewide population-based database which collects all cancer cases and deaths among Mississippi residents. The MCR is registered in the NPCR and North American Association of Central Cancer Registries (NAACCR). Utilizing information collected by the MCR, the Mississippi Department of Health can develop programs to better address Mississippi’s cancer program needs.

Lung and bronchus (includes non-invasive and invasive) cancer incidence and mortality data were obtained from the MCR for 2008-2012. Incidence and mortality rates are presented as an average annual number of new cases and deaths per 100,000 persons, adjusted to the 2000 U.S. Standard population. Rates less than 15 cases or deaths in each year were not calculated.

Incidence is the number of new cases that have occurred during a specified period (years 2008 to 2012) divided by the population at risk during that period and then multiplied by a multiplier $(100,000)$ (NCI, 2007). Non-invasive cancer describes the disease that has not spread outside the tissue in which it began (NCI, 2007). Invasive cancer is defined as the spread beyond the layer of tissue in which it developed and is growing into surrounding, healthy tissues (NCI, 2007). Mortality is the number of people who died due to cancer during a given period (years 2008 to 2012) divided by the population at risk during that period (NCI, 2007). The result is then multiplied by a multiplier $(100,000)$. Age-adjusted rates ensure that differences in incidence (new cases) and mortality (deaths) from one year to another or between one geographic area and another are not due to differences in the age distribution of the populations being compared. $95 \%$ confidence intervals were also used.

\section{RESULTS}

\section{Incidence}

During 2008-2012, 12,579 people (overall rate of 78.63 per 100,000) were diagnosed with lung and bronchus cancer in Mississippi of whom were 9,133 (79.7) Whites, 3,390 (76.1) Blacks 7,490 (107.3) males, and 5,089 (57.4) females. Lung cancer incidence rates were the highest among males (107.3), Whites (79.7), persons aged 75 to 79 years (513.8), and those living in District IX (85.2) The breakdown by race, age, gender, and 9 Public Health Districts in Mississippi were higher among males (107.3); 95 CI (104.78-109.80) than females (57.4); 95 CI (55.7758.97). Table 1 shows that Whites (79.7); 95 CI (78.08-81.39) were diagnosed more compared to Blacks (76.1); 95 CI (73.43-78.76). Whites who lived in urban areas are diagnosed at a higher rate (80.96) compared to their counterparts. In regards to race and gender, Black males (116.8); CI (111.46-122.08) had a higher incidence compared to White males (103.7); 95 CI (100.88-106.62). In contrast, White females (61.8); 95 CI (59.82-63.80) had a higher incidence compared to Black females (47.9\%); $95 \mathrm{CI}(47.27-50.80)$. By age group, incidence had the highest among persons aged 75-79 (513.8) compared to the other 11 groups. Due to geographic differences, the death rate ranged from a low rate of (365.4) diagnosis per 100,000 (Greene County) to a high rate (617.1) diagnosis per 100,000 (Yalobusha County).When analyzed by Mississippi Public Health Districts, District 9 (Coastal Area- 
European Journal of Environment and Public Health, 1(1), 01

Table 1. Age-Adjusted Demographic Characteristics for Lung \& Bronchus Cancer Incidence in Mississippi, 20082012

\begin{tabular}{|c|c|c|c|c|c|c|}
\hline & \multicolumn{3}{|c|}{ Total } & \multicolumn{2}{|c|}{ Blacks } & \multirow{2}{*}{$\begin{array}{c}\text { Whites } \\
\text { Rate(CI) } \\
\text { 79.72(78.08-81.39) }\end{array}$} \\
\hline & $\mathrm{N}=12579$ & $\begin{array}{c}\text { Rate (CI) } \\
78.63(77.24-80.03) \\
\end{array}$ & $\mathrm{N}=3390$ & $\begin{array}{c}\text { Rate(CI) } \\
76.06(73.43-78.76) \\
\end{array}$ & $\mathrm{N}=9133$ & \\
\hline \multicolumn{7}{|l|}{ Age } \\
\hline $30-34$ & 14 & 1.49 & 6 & 1.59 & 8 & 1.47 \\
\hline 35-39 & 34 & 3.66 & 9 & 2.57 & 24 & 4.28 \\
\hline $40-44$ & 127 & 13.35 & 40 & 11.58 & 87 & 14.79 \\
\hline $45-49$ & 459 & 44.73 & 172 & 47.08 & 282 & 43.74 \\
\hline $50-54$ & 928 & 89.33 & 371 & 100.91 & 552 & 84.03 \\
\hline 55-59 & 1324 & 141.43 & 478 & 150.93 & 842 & 138.52 \\
\hline 60-64 & 1734 & 215.84 & 500 & 214.48 & 1227 & 218.56 \\
\hline 65-69 & 2162 & 353.65 & 560 & 356.71 & 1593 & 355.02 \\
\hline $70-74$ & 2094 & 443.53 & 457 & 392.49 & 1630 & 463.58 \\
\hline 75-79 & 1815 & 513.78 & 424 & 516.60 & 1381 & 573.79 \\
\hline $80-84$ & 1209 & 466.15 & 209 & 355.56 & 993 & 498.62 \\
\hline $85+$ & 670 & 298.19 & 160 & 282.94 & 509 & 304.58 \\
\hline \multicolumn{7}{|l|}{ Gender } \\
\hline Males & 7490 & $\begin{array}{c}107.27(104.76- \\
109.80)\end{array}$ & 2169 & $\begin{array}{c}116.69(111.46- \\
122.08)\end{array}$ & 5291 & $\begin{array}{c}103.72 \\
(100.88,106.62)\end{array}$ \\
\hline Females & 5089 & $57.35(55.71-58.97)$ & 1221 & $47.98(45.27-50.80)$ & 3842 & $61.78(59.82-63.80)$ \\
\hline \multicolumn{7}{|c|}{ Public Health Districts } \\
\hline I & 1298 & $81.56(77.10-86.20)$ & 299 & $70.10(62.01-78.88)$ & 998 & $86.30(80.95-91.92)$ \\
\hline II & 1673 & $81.86(77.94-85.93)$ & 234 & 76.87 (68.98-87.85) & 1438 & $82.92(78.65-87.38)$ \\
\hline III & 912 & $78.23(70.29-83.56)$ & 462 & 75.87 (68.89-83.34) & 448 & $80.94(73.43-89.11)$ \\
\hline IV & 1028 & $74.83(70.29-79.60$ & 323 & 75.15 (66.96-84.04) & 705 & $74.42(68.97-80.22)$ \\
\hline $\mathrm{V}$ & 2399 & $76.15(73.08-79.31)$ & 869 & 73.84 (68.80-79.13) & 1522 & $77.02(73.15-81.05)$ \\
\hline VI & 1063 & $75.03(70.55-79.73)$ & 292 & $71.06(62.95-79.89)$ & 768 & $77.83(72.36-83.65)$ \\
\hline VII & 787 & $73.14(68.07-78.51)$ & 334 & $75.42(75.42-94.24)$ & 452 & $67.08(60.94-73.75)$ \\
\hline VIII & 1259 & $77.16(72.91-81.59)$ & 285 & $79.32(70.07-89.37)$ & 969 & $76.52(71.73-81.57)$ \\
\hline$\overline{\mathrm{IX}}$ & 2159 & 85.17 (81.55-88.91) & 292 & $83.97(74.07-94.75)$ & 1832 & $85.38(81.56-89.45)$ \\
\hline \multicolumn{7}{|c|}{ Geographic Region } \\
\hline Urban & 5289 & $79.41(77.24-81.61)$ & 2171 & $74.30(69.97-78.81)$ & 4028 & $80.96(78.45-83.54)$ \\
\hline Rural & 7290 & $78.22(76.42-80.06)$ & 1219 & $77.00(73.71-80.41)$ & 5104 & $78.96(76.78-81.19)$ \\
\hline
\end{tabular}

MS Cancer Registry, 2017

Pearl River, Stone, George, Hancock, Harrison, and Jackson Counties) and District II (Northeast Area-Alcorn, Benton, Itawamba, Lafayette, Lee, Marshall, Prentiss, Pontotoc, Tippah, Tishomingo, and Union) had higher rates at 85.2;(95 CI 81.55-88.91) and 81.9 (77.94-85.93) respectively compared to the others. The District had the highest incidence was District IX (Coastal Area: Pearl River, Stone, George, Hancock, Harrison, and Jackson Counties) (85.2); 95 CI (81.55-88.91), respectively (Table 1).

\section{Mortality}

In Mississippi, 9,688 people (overall rate of 61.13 per 100,000) died with lung and bronchus cancer in Mississippi of whom were 272 (61.5) Whites, 2,638 (60.2) Blacks, 6,000 (88.2) males, and 3,688 (41.26) females. Lung cancer mortality rates were the highest among males (88.7), Whites (61.47), persons aged 80 to 84 years (424.5), those living in District IX (65.6) and rural; (62.3) areas. The breakdown by race, age, gender, and 9 Public Health Districts in Mississippi were higher among males (88.2); 95 CI (85.88-90.50) than females (41.3); 95 CI (39.93-42.62). Table 2 shows that Whites (61.5); 95 CI (60.03-62.94) died more during this period of time compared to Blacks (60.2); 95 CI (51.89-62.67). However, the Black population who lived in rural areas die at a higher rate (62.9). In regards to race and gender, Black males (97.6); CI (92.79-102-69) died at a higher rate compared to White males (84.8); 95 CI (82.24-87.50). In contrast, White females (44.02); 95 CI (42.38-45.71) had a higher incidence compared to Black females (34.99) 95 CI (47.27-50.80). By age group, incidence had the highest among persons aged 80-84 (424.5) compared to the other 11 groups. Due to geographic differences, the death rate ranged from a low rate (34.4) diagnosis per 100,000 (Franklin County) to a high rate (87.5) diagnosis per 100,000 (Madison).When analyzed by Mississippi Public Health Districts, District IX (Coastal Area- Pearl River, Stone, George, Hancock, Harrison, and Jackson counties) and District I (Northwest Area-Coahoma, Desoto, Grenada, 
Table 2. Age-Adjusted Demographic Characteristics for Lung \& Bronchus Cancer Mortality in Mississippi, 2008-2012

\begin{tabular}{|c|c|c|c|c|c|c|}
\hline & \multicolumn{3}{|c|}{ Total } & \multicolumn{2}{|c|}{ Blacks } & \multirow{2}{*}{$\begin{array}{c}\text { Whites } \\
\text { Rate(CI) } \\
61.47(60.03- \\
62.94)\end{array}$} \\
\hline & $N=9688$ & $\begin{array}{c}\text { Rate (CI) } \\
61.13(59.90- \\
62.37)\end{array}$ & $N=2638$ & $\begin{array}{c}\text { Rate(CI) } \\
60.24 \text { (57.89- } \\
62.67)\end{array}$ & $\mathrm{N}=7011$ & \\
\hline \multicolumn{7}{|l|}{ Age } \\
\hline $30-34$ & 6 & 0.64 & NS a & NS a & NS a & NS a \\
\hline $35-39$ & 12 & 1.29 & NS a & NS a & 9 & 1.61 \\
\hline $40-44$ & 70 & 7.36 & 21 & 6.08 & 49 & 8.33 \\
\hline $45-49$ & 310 & 30.21 & 136 & 37.22 & 172 & 26.68 \\
\hline$\overline{50-54}$ & 607 & 58.43 & 243 & 66.10 & 362 & 55.10 \\
\hline $55-59$ & 931 & 99.45 & 350 & 110.51 & 580 & 95.42 \\
\hline $60-64$ & 1250 & 155.60 & 393 & 168.58 & 846 & 150.70 \\
\hline 65-69 & 1544 & 252.56 & 418 & 266.26 & 1117 & 248.94 \\
\hline $70-74$ & 1605 & 339.96 & 357 & 306.61 & 1243 & 353.51 \\
\hline $75-79$ & 1490 & 421.78 & 333 & 405.73 & 1151 & 428.22 \\
\hline $80-84$ & 1101 & 424.51 & 212 & 360.66 & 888 & 445.90 \\
\hline $85+$ & 761 & 338.69 & 170 & 300.62 & 589 & 352.45 \\
\hline \multicolumn{7}{|l|}{ Gender } \\
\hline Males & 6000 & $88.17(85.88-90.50)$ & 1750 & 97.7 (92.79-102.69) & 4231 & $84.84(82.24-87.50)$ \\
\hline Females & 3688 & $41.26(39.93-42.62)$ & 888 & $34.99(32.68-37.41)$ & 2780 & $44.02(42.38-45.71)$ \\
\hline \multicolumn{7}{|c|}{ Public Health Districts } \\
\hline $\bar{I}$ & 1021 & $65.26(61.25-69.46)$ & 247 & $59.48(51.96-67.71)$ & 771 & $67.83(63.07-72.88)$ \\
\hline II & 1320 & $65.07(61.58-68.72)$ & 184 & $62.18(53.21-72.16)$ & 1134 & $65.74(61.94-69.73)$ \\
\hline III & 755 & $64.59(60.01-69.44)$ & 372 & $61.37(55.11-68.13)$ & 383 & $67.35(60.65-74.70)$ \\
\hline IV & 793 & $57.75(53.77-61.95)$ & 267 & $61.56(54.18-69.62)$ & 524 & $55.05(50.40-60.05)$ \\
\hline $\mathrm{V}$ & 1726 & $55.38(52.75-58.10)$ & 626 & $54.48(50.12-59.10)$ & 1097 & $55.58(52.30-59.02)$ \\
\hline $\mathrm{VI}$ & 873 & $61.94(57.86-66.24)$ & 240 & $59.17(51.76-67.32)$ & 626 & $63.35(58.43-68.61)$ \\
\hline VII & 633 & $58.94(54.39-63.78)$ & 264 & $66.60(58.62-75.34)$ & 7011 & $61.47(60.03-62.94)$ \\
\hline VIII & 938 & $58.00(54.32-61.87)$ & 225 & $64.68(56.24-23.95)$ & 71 & $56.39(52.29-60.75)$ \\
\hline IX & 1629 & $65.61(67.40-68.94)$ & 213 & $66.40(57.25-76.50)$ & 1396 & $66.01(62.54-69.63)$ \\
\hline \multicolumn{7}{|c|}{ Geographic Region } \\
\hline Urban & 3898 & $59.67(57.78-61.61)$ & 81 & $55.70(51.89-59.69)$ & 2994 & $61.00(58.81-63.25)$ \\
\hline Rural & 5790 & $62.33(60.72-63.97)$ & 1757 & $62.94(59.95-66.04)$ & 4017 & $61.99(60.07-63.96)$ \\
\hline
\end{tabular}

MS Cancer Registry, 2017

${ }^{a}$ Counts/Rates are suppressed if less than 5 cases were reported in the specified category

Panola, Quitman, Tate, Tallahatchie, Tunica, and Yalobusha counties) had higher rates at 65.6;(95 CI 62.0-65.9) and 65.3 (61.25-69.46) respectively compared to the others (Table 2).

\section{DISCUSSION}

The data used included the incidence and mortality rates from all 82 counties in the state. We present data from 2008-2012 on lung and bronchus cancer incidence and mortality based on, race, age, sex, and geographic locations. Overall, Whites are more likely to be diagnosed, but Blacks are more likely to die from lung cancer, regardless of gender. But, there is a disproportionate burden by race and gender, Black males are diagnosed and die at a higher rate compared to their counterparts. The increased lung cancer incidence rates observed among Black males may be due to increased susceptibility to smoking. In 2012, the increased rate of smoke prevalence was more than 2 times higher among White females compared to Black females (NCI, 2007). However, several other factors may contribute to the racial and regional variation in incidence and mortality rates; such as the prevalence of certain risk factors (environmental, occupational, and behavioral), socioeconomic status, and lung cancer screening behaviors.

\section{CONCLUSION}

The findings conclude racial, gender, age, and geographic disparities in lung cancer incidence and mortality and it is suggested that there is a need for more effective community-based interventions and preventative measures 
for cultural sensitive groups to reduce the burden of lung cancer in Mississippi. Our observations highlight district patterns in racial disparities in cancer incidence and mortality that denotes more extensive collaborations and evaluation to offset potentially district and county-specific determinants. Targeted race and geographic locationspecific prevention, treatment, and follow-up practices are needed to address the observed differences. This can be used to guide the cancer control planning efforts of governmental entities, district coalitions, cancer district coalitions, and non-profit health agencies that serve the communities within each underserved geographic location. Further surveillance in lung cancer incidence and mortality within the Public Health Districts are warranted. Effective cancer prevention and control is imperative and these results can be utilized to anchor modified risk factors specific toward high-risk populations at a local level. In addition, the data open the possibility of providing to the state legislature, targeted information in regards to cancer rates among their constituents and to have a better understanding of Mississippi's cancer incidence and mortality rates. For this reason, educational efforts such as public service announcements may serve as vehicles to increase the public's knowledge, awareness, and practices of the enormous toll of lung cancer.

\section{REFERENCES}

American Lung Association (2015). Cutting Tobacco's Rural Roots: Tobacco Use in Rural Communities. Chicago: American Lung Association, 2015. Available at: http://www.lung.org/assets/documents/research/cuttingtobaccos-rural-roots.pdf

Giddens, J.F. (2013). Cellular Regulation, Concepts for Nursing Practice [Kindle] (p.107).

Mississippi Cancer Registry. Cancer rates.info (2017). Age-Adjusted Cancer Incidence and Mortality Rates in Mississippi, 2008-2012. Available at: http:// cancer-rates.info/ms/ (Assessed 3 March 2017).

Mississippi Department of Health (2006). Mississippi Comprehensive Cancer Control Plan 2006-2011. Available at: http://msdh.ms.gov/msdhsite/index.cfm/43,1596,292,pdf/MS_CompehensiveCancerPlan.pdf

National Cancer Institute (2008). Understanding Cancer. Available at: https://www.cancer.gov/aboutcancer/understanding/what-is-cancer

National Cancer Institute (2007). Type of Cancer Statistics. Division of Cancer Control and Population Sciences. Available at: https://surveillance.cancer.gov/statistics/types/incidence.html (Assessed 4 March 2017).

Nguyen, K., Marshall, L., Hu, S., Neff, L. (22 May 2015). State-Specific Prevalence of Cigarette Smoking and Smokeless Tobacco Use among Aged $\geqslant 18$ Years-United States, 2011-2013, Morbidity and Mortality Weekly Report (MMWR). Available at: https://www.cdc.gov/mmwr/preview/mmwrhtml/mm6419a6.htm (Assessed 9 March 2017).

Singh, G.K., Williams, S.D., Siahpush, M., Mulhollen, A. (2011). Socioeconomic, Rural-Urban, and Racial Inequalities in US Cancer Mortality: Part I-All Cancers and Lung Cancer and Part II-Colorectal, Prostate, Breast, and Cervical Cancers, Journal of Cancer, 11:27 pgs. doi: 10.1155/2011/107497.

Underwood, J.M., Townsend, J.S., Tae, E., Davis, S.P., Stewart, S.L., White, A., Momin, B., Fairley, T.L. (2012). Racial and Regional Disparities in Lung Cancer Incidence, Cancer, 118(7):1910-1918. doi: 10.1002/cncr.26479.

U.S. Department of Health and Human Services (2006). The Health Consequences of Involuntary Exposure to Tobacco Smoke: A Report of the Surgeon General. Rockville, MD: Centers for Disease Control and Prevention, Coordinating Center for Health Promotion, National Center for Chronic Disease Prevention and Health Promotion, Office on Smoking and Health. Available at: https://www.surgeongeneral.gov/library/reports/50-years-of-progress/ (Assessed 9 March 2017).

Wong, M.D., Ettner, S.L., Boscardin, W.J., Shapiro, M.F. (2009). The Contribution of Cancer Incidence, Stage, Diagnosis, and Survival to Racial Difference Years Life Expectancy, Journal of General Internal Medicine, 24(4), 475-481. doi: 10.1007/s11606-009-0912-1.

Xiaoling, N. Pawlish, K.S., Roche, L.M. (2010). Cancer Survival Disparities by Race/Ethnicity and Socioeconomic Status in New Jersey, Journal of Health Care for the Poor and Underserved, 21(1),144-160. doi: 10.1353/hpu.0.0263. 